\title{
A family study of Charcot-Marie-Tooth disease
}

\author{
A P BROOKS* AND A E H EMERY
}

From the University Department of Human Genetics, Western General Hospital, Edinburgh EH4 $2 X U$

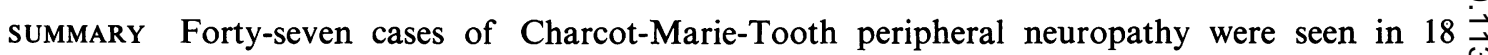
families within a defined area, with a disease prevalence of 1 in 16400 . Maximum motor nerve $\stackrel{\omega}{\mathscr{\omega}}$ conduction velocity (MNCV) measurement divided off two types of neuropathy (MNCV $<30 \mathrm{~ms}^{-1} \bar{\Xi}$ and $>40 \mathrm{~ms}^{-1}$ ), but did not distinguish clinically affected from normal in families whose probands had median nerve $\mathrm{MNCV}>40 \mathrm{~ms}^{-1}$. In the neuronal type of neuropathy $\left(\mathrm{MNCV}>40 \mathrm{~ms}^{-1}\right)$ two genotypes were seen, autosomal dominant (ADN) and autosomal recessive (ARN). Most cases with $\infty_{\infty}^{\circ}$ the demyelinating type (MNCV $<30 \mathrm{~ms}^{-1}$ ) had an autosomal dominant genotype (ADD) but one ${ }^{\infty}$ family had possible $X$ linked recessive inheritance (XRD). In one autosomal dominant family a father and son had different electrophysiological types of neuropathy.

Peroneal muscle weakness was progressive with age in the ADD genotype and certain patterns of phenotypic features were associated with the major genotypes. Age of onset was not found to be $\vec{\varphi}$ reliable in distinguishing genotypes. Care is needed when counselling isolated male cases because of $\infty_{N}^{\infty}$ asymptomatic affected females in the autosomal dominant genotypes, and the possibility of ill defined $\mathrm{X}$ linked forms.

The term Charcot-Marie-Tooth disease is used here to describe those inherited, chronic, mixed but predominantly motor, peripheral neuropathies whose clinical features include peroneal and distal leg muscle weakness and wasting, foot drop, and often foot deformity of the pes cavus type. This definition is derived from analysis of the original papers of Charcot and Marie ${ }^{1}$ and Tooth ${ }^{2}$ and is in accord with that given by de Recondo. ${ }^{3}$ The eponym is not used synonymously with peroneal muscular atrophy, since the variously inherited peripheral neuropathies of Charcot-Marie-Tooth disease are regarded as one pathological cause of the clinical syndrome of peroneal muscular atrophy. ${ }^{4}$

This paper describes an investigation of an unselected group of patients with established Charcot-Marie-Tooth disease. The family study was designed to ascertain all cases in a defined geographical area, to establish the degree of genetic heterogeneity, and particularly to correlate phenotypic features with the genotypes identified as an aid to genetic counselling. All subjects were seen within one year and were personally examined.

*Present address:

Department of Medicine, Addenbrooke's Hospital, Cambridge CB2 2QQ.

Received for publication 24 April 1981

\section{Patients and methods}

Probands living in the geographical area under study $\overline{\overline{0}}$ were ascertained from the records of the University Department of Human Genetics, Edinburgh, and $\underset{F}{F}$ from the local orthopaedic, neurological, and paediatric clinics. All probands and secondary cases found in their families had clear clinical evidence of $\underline{0}$ motor and sensory abnormalities indicating peripheral neuropathy.

Affected subjects were classified as having a $ᄋ$ demyelinating or neuronal type of neuropathy (equivalent in terminology to type I and type II 옹 hereditary motor and sensory neuropathy respect- $\rightarrow$ ively) on the basis of median or ulnar motor nerve conduction velocity (MNCV) as described by Thomas and colleagues. ${ }^{5-7}$ In the present study there was a clear division into cases with MNCV less than 30 or greater than $40 \mathrm{~ms}^{-1}$.

Both types of peripheral neuropathy divided in $\square$ this way contained families belonging to possibly two 0 different genotypes separated on the basis of family $\underset{\mathbb{D}}{\overparen{D}}$ history, verified by clinical examination and $\stackrel{?}{+}$ measurement of motor nerve conduction velocity.

Disease prevalence and relative frequency of genotypes

Of the 47 cases seen in 18 families, 46 lived in the $\stackrel{\mathbb{Q}}{\Omega}$ geographical area served by the Scottish Lothian 88 
TABLE 1 Observed genotypes in 18 families

\begin{tabular}{lcll}
\hline Families & Cases & $\begin{array}{l}\text { Maximum motor nerve } \\
\text { conduction velocity }(\mathrm{ms})\end{array}$ & Genotype \\
\hline A-J (9) & $1-33(33)$ & $<30$ & ADD \\
K-M (3) & $34-39(6)$ & $>40$ & ADN \\
N-S (5) & $40-45(6)$ & $>40$ & ARN \\
T (1) & $46+47(2)$ & $<30$ & XRD $^{*}$ \\
\hline
\end{tabular}

ADD, autosomal dominant demyelinating

ADN, autosomal dominant neuronal

ARN, autosomal recessive neuronal

$\mathrm{XRD}, \mathrm{X}$ linked recessive demyelinating. ${ }^{*}$ Possible genotype-see text.

Health Board with a total population of 750000 . An overall minimal estimate of the disease prevalence is 1 in 16400 .

Four genotypes were identified on the basis of clinical examination and forearm nerve maximum motor conduction velocity, and their relative frequencies are shown in table 1 . Demyelinating and neuronal refer to the presumed peripheral nerve pathology indicated by maximum motor nerve conduction velocities of respectively less than 30 or greater than $40 \mathrm{~ms}^{-1}$. Autosomal dominant demyelinating genotype is the commonest (33 of 47 cases), but families with neuronal types ${ }^{8}$ are as common as those with demyelinating. ${ }^{9}$

\section{Maximum motor nerve conduction velocity studies}

Maximum motor nerve conduction velocity (MNCV, $\mathrm{ms}^{-1}$ ) in the elbow-wrist segment of the right median or ulnar nerve (forearm nerve) was measured in 40 cases, 27 of whom had a velocity $<30 \mathrm{~ms}^{-1}$ and 13 a velocity $>40 \mathrm{~ms}^{-1}$. Measurements were carried out using a Medelec MS4 Portable Electr omyograph. A surface stimulation and recording technique was used with skin temperature always in the range 30 to $33^{\circ} \mathrm{C}$. Normal values were obtained for 30 healthy adults. Mean values for clinically affected and normal members of the families demonstrating the four genotypes are shown in table 2 , together with normal values obtained in this study.

TABLE 2 Mean median and ulnar nerve maximum motor conduction velocities $(\mathrm{ms})$ in patients with Charcot-Marie-Tooth disease and their normal relatives

\begin{tabular}{llrl}
\hline Genotype & & No & Mean \\
\hline ADD & Affected & 26 & $21 \cdot 2$ \\
& Normal & 5 & $61 \cdot 2$ \\
ADN & Affected & 6 & $54 \cdot 2$ \\
& Normal & 1 & $55 \cdot 3$ \\
ARN & Affected & 6 & $49 \cdot 5$ \\
& Normal & 6 & $55 \cdot 7$ \\
Family T & Affected & 2 & $24 \cdot 5$ \\
& Normal & 1 & $56 \cdot 8$ \\
& Mother & 1 & $38 \cdot 3$ \\
\hline
\end{tabular}

Normal values (mean $\pm 2 \mathrm{SD}$ ) for 30 median nerves $49 \cdot 7-69 \cdot 3$ and 25 ulnar nerves $51 \cdot 6-72 \cdot 0 \mathrm{~ms}$.

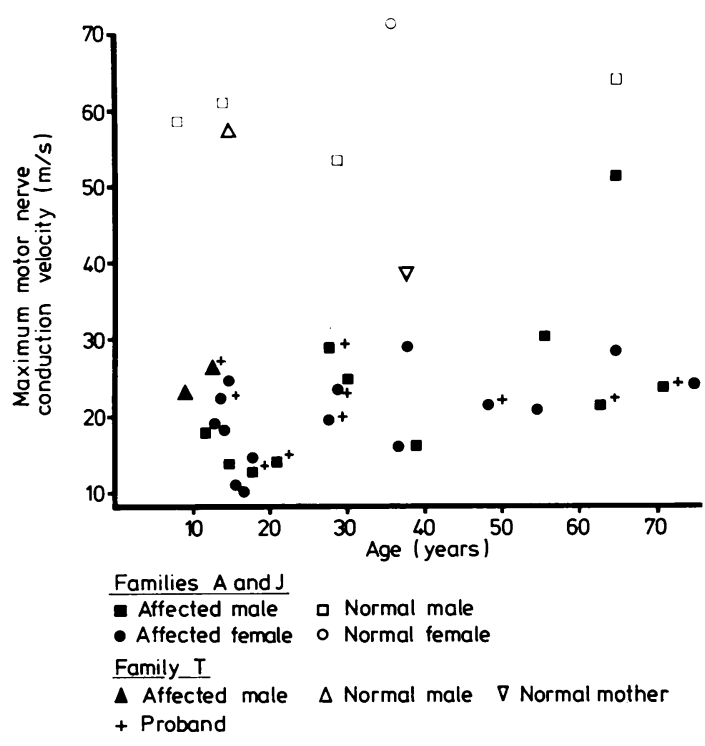

FIG 1 Forearm nerve maximum motor conduction velocities in families $A$ to $J$ and $T$ whose probands have conduction velocities $<30 \mathrm{~ms}$.

In fig 1 forearm MNCV is plotted for members of families $A$ to $J$ and $T$, whose probands have conduction velocities $<30 \mathrm{~ms}^{-1}$. It should be noted that one definitely affected male of 65 years (the father of the proband in family $\mathrm{H}$ ) had a median MNCV of $51.0 \mathrm{~ms}^{-1}$, which is in the normal range. Similarly, the presumed carrier mother in family $T$ had a median MNCV of $38.3 \mathrm{~ms}^{-1}$, the only measurement obtained of neither $<30 \mathrm{~ms}^{-1}$ nor $>40 \mathrm{~ms}^{-1}$ in any person

In fig 2 forearm MNCV is plotted for members of families $\mathrm{K}, \mathrm{L}, \mathrm{M}$, and $\mathrm{N}$ to $\mathrm{S}$, and whether affected or normal all had velocities $>40 \mathrm{~ms}^{-1}$.

Values for peroneal MNCV in 19 subjects are shown in table 3.

TABLE 3 Peroneal nerve maximum motor conduction velocities ( $\mathrm{ms}$ ) in affected subjects and normal first degree relatives

\begin{tabular}{llll}
\hline Genotype & & No & Mean \\
\hline ADD & Affected & 6 & $19 \cdot 1$ \\
& Normal & 5 & $55 \cdot 5$ \\
ADN & Affected & 2 & $48 \cdot 4$ \\
& Normal & 1 & $51 \cdot 6$ \\
ARN & Affected & 1 & $34 \cdot 1$ \\
& Normal & 4 & $50 \cdot 8$ \\
\hline
\end{tabular}

Normal (mean \pm 2 SD) for 30 peroneal nerves $63 \cdot 6-38 \cdot 0 \mathrm{~ms}$. 


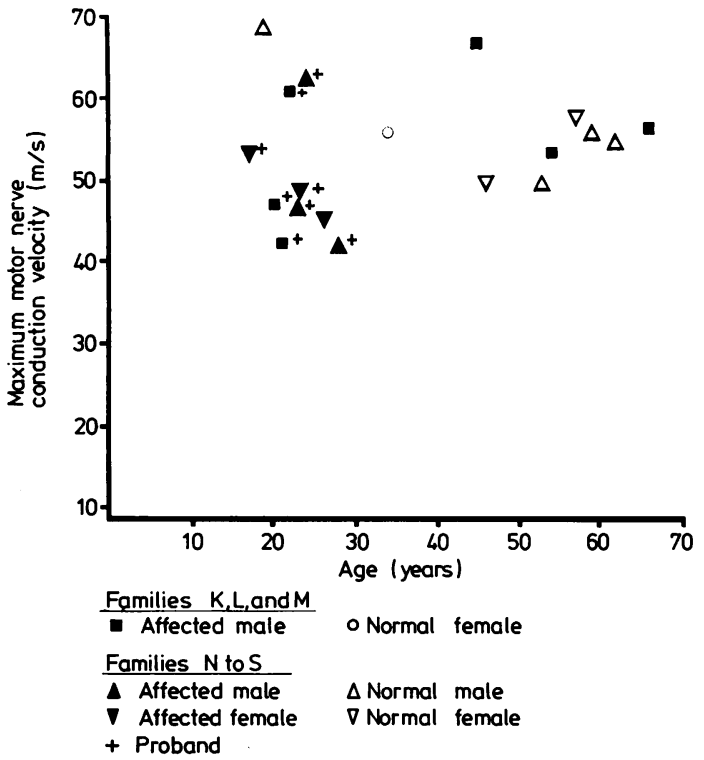

FIG 2 Forearm nerve maximum motor conduction velocities in families $K$ to $S$ whose probands have conduction velocities $>40 \mathrm{~ms}$.

\section{Phenotypic features related to genotypes}

\section{AGE OF ONSET}

On the basis of age of onset it was not possible to distinguish between the four genotypes. Means (and ranges) for the four genotypes were: ADD, 11.0 (5-26); ADN, 8.75 (4-13); ARN, 10·75 (3-20); and possible XRD, 7 and 8 years.

The problem of subjectivity of assessment of age of onset was illustrated with respect to hand involvement, for 17 of 20 cases who denied hand symptoms had in fact clinical intrinsic hand muscle disease.

SYMMETRY OF INVOLVEMENT OF LOWER LIMBS This was judged by questioning, clinical examination, and history of surgical intervention. In all, 24 of 29 cases of ADD genotype, and four of four with ADN showed evidence of asymmetry of involvement, but only one of six in ARN genotype.

\section{PATTERN OF MUSCLE WEAKNESS}

Muscle weakness in members of the ADD genotype was progressive with age, with involvement first of the distal lower limb often with foot deformity, then later the proximal leg, hand, and forearm. Such a clear progression was not seen in the ADN genotype where muscle weakness may only be slight, but there
TABLE 4 Strength of foot eversion by the peroneal muscles: mean values for MRC grade and ergometer force

\begin{tabular}{llclll}
\hline Genotype & Cases & $\begin{array}{l}\text { Ages } \\
(\mathrm{yr})\end{array}$ & $\begin{array}{l}\text { MRC } \\
\text { grade }\end{array}$ & $\begin{array}{l}\text { Force }(\mathrm{kg}) \\
(\mathrm{mean} \pm S D)\end{array}$ \\
\hline (a)* & ADD & $1-8$ & $75-63$ & 3 & $2 \cdot 3 \pm 3 \cdot 1$ \\
(b) $\dagger$ & ADD & $10-13$ & $56-49$ & 4 & $6 \cdot 1 \pm 1 \cdot 4$ \\
(c) $\ddagger$ & ADD & $14-25$ & $39-18$ & 4 & $6 \cdot 8 \pm 2 \cdot 2$ \\
(d) $\S$ & ADN & $34-39$ & $20-66$ & $4 / 4+$ & $7 \cdot 7 \pm 1 \cdot 8$ \\
(e) & ARN & $40-45$ & $17-28$ & $3 / 4-$ & $3 \cdot 0 \pm 4 \cdot 0$ \\
\hline
\end{tabular}

$p$ values

*(a) v (b), (c), and (d): 0.01 $>p>0.001$

(b) $\vee(e): 0.05>p>0.02$

$\ddagger$ (c) $v$ (e): $p<0.001$

$\S(d) \vee(e): 0.01>p>0.001$

were fewer cases. In contrast, in the ARN genotype marked muscle weakness was present at a younger age, with proximal and distal leg and hand involvement in the youngest patient, aged 17 years.

\section{STRENGTH OF THE PERONEAL MUSCLES}

The force (measured in $\mathrm{kg}$ ) needed to overcome eversion of the foot because of the peroneal muscles was measured using an ergometer and assessed clinically on the MRC scale. The mean strengths of five groups of cases in families $\mathrm{A}$ to $\mathrm{S}$ divided on the basis of age and genotype are shown in table 4, where statistically significant differences exist between certain groups. Thus, strength is preserved longest in the ADN genotype, but weakness is progressive with age in the ADD genotype and marked in ARN cases.

The unusual degree of weakness in the ARN genotype with age is illustrated in fig 3 . Here age of affected subjects plotted against strength of peronei for 25 adults of the ADD genotype shows a significant negative correlation $(r=-0 \cdot 54)$. Observed mean strength $\left(\mathrm{x}_{1}\right)$ of the peronei in the ADN genotype was $7 \cdot 7 \mathrm{~kg}$. If these cases had belonged to the ADD genotype their expected mean age would be 37.5 years $\left(y_{1}\right)$. In fact, the observed mean age was $36 \cdot 6$ years indicating muscle weakness no worse than would be expected for age. In contrast, the mean strength of the peronei in the ARN genotype was $3.0 \mathrm{~kg}\left(\mathrm{x}_{2}\right)$ giving an expected mean age of 53.4 years $\left(y_{2}\right)$ had the cases been of the ADD genotype. Their observed mean age was 23.5 years showing how much more severely affected people of the ARN genotype appear to be for their age.

\section{MUSCLE WASTING}

The pattern of muscle wasting confirmed by comparison with measurements in controls follows that of muscle weakness, for example, calf muscle wasting is progressive with age in ADD type, but may be present in young cases of ARN type. 


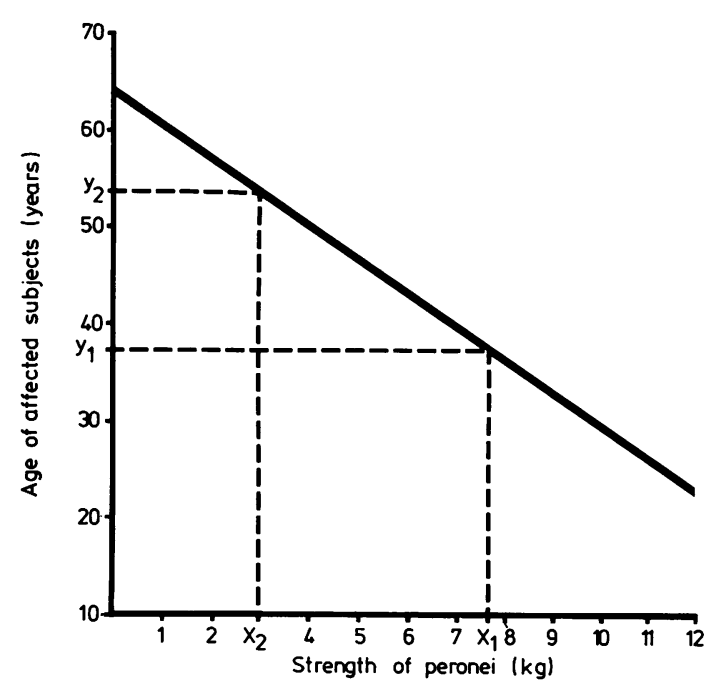

FIG 3 Strength of peronei against age for 25 adults of $A D D$ genotype. $x_{1}$ is mean strength of peronei $(7.7 \mathrm{~kg})$ in ADN genotype giving $y_{1}$ the expected mean age (37.5 yr). Mean observed age is $36.6 \mathrm{yr} . x_{2}$ is mean strength of peronei $(3.0 \mathrm{~kg})$ in ARN genotype giving $y_{2}$ the expected mean age (53.4 yr). Mean observed age is $23.5 \mathrm{yr}$.

\section{SENSORY LOSS}

No clear pattern for sensory loss was observed, but in the ADD type sensory loss became more extensive with age, and in five of six ARN cases more than one sensory modality was lost at presentation.

\section{ABSENCE OF TENDON REFLEXES}

Pathological changes in the tendon reflexes were seen in all four genotypes. Only one of 33 ADD cases had preserved leg reflexes, while 30 of 33 had either both ankle or both knee reflexes absent and 21 had all leg reflexes absent. Furthermore, 27 of the 33 had two or more arm reflexes absent and 11 had total areflexia. In contrast, four of six $\mathrm{ADN}$ cases had all reflexes present and the other two had lost one ankle reflex each. In the ARN type all six cases had either both knee or both ankle reflexes absent, four had lost two or more arm reflexes, and three had total areflexia (table 5).

\section{PES CAVUS, TREMOR, AND SCOLIOSIS}

Pes cavus occurred in 19 of 25 ADD cases over 18 years. Foot drop developed in older patients. Classical pes cavus was not seen in ARN type
TABLE 5 Changes in tendon reflexes in 45 cases by genotype

\begin{tabular}{llll}
\hline & $A D D(33)$ & $A D N(6)$ & $A R N(6)$ \\
\hline Both ankle reflexes present & 1 & 4 & 1 \\
One ankle reflex present & 3 & 2 & 0 \\
Both ankle reflexes absent & 29 & 0 & 5 \\
Both knee reflexes absent & 22 & 0 & 5 \\
All leg reflexes absent & 21 & 0 & 4 \\
Two or more arm reflexes absent & 27 & 0 & 4 \\
Total areflexia & 11 & 0 & 3 \\
\hline
\end{tabular}

although arches were high and bilateral foot drop usual.

Fifteen cases had a terminal action tremor, 12 of ADD and three of ADN type. Seven of these, all males, had scoliosis as did one other case without tremor.

POSSIBLE X LINKED RECESSIVE CASES

Two affected sons in one family $(T)$ were seen aged 9 and 13 years. They have not been included in the above analysis but had clinical features similar to cases of an equal age in the ADD genotype, principally high arches, distal leg muscle weakness, and absent leg tendon reflexes. Both parents and a third son were clinically entirely normal.

\section{Discussion}

Dyck and Lambert ${ }^{89}$ showed that among patients presenting with a peripheral neuropathy (corresponding to the term Charcot-Marie-Tooth disease as defined here) there were two groups, divisible on the basis of motor nerve conduction velocity. These were a 'hypertrophic type' with autosomal dominant inheritance and reduced motor nerve conduction velocity, and a 'neuronal type' with autosomal dominant inheritance and normal motor nerve conduction velocity. The types were subsequently renamed hereditary motor and sensory neuropathy type I and type II, respectively. ${ }^{10}$ This division alone does not allow for the degree of genetic heterogeneity found in these disorders as demonstrated by the present study of a defined population.

The present position with respect to genetic heterogeneity in Charcot-Marie-Tooth disease is summarised in table 6 . The autosomal dominant forms of hereditary motor and sensory neuropathy type I and II, here called demyelinating and neuronal neuropathy, are well established. 58911 The evidence for autosomal recessive forms is less clear cut. Dyck and Lamber $^{8}$ described eight probands and two affected sibs with clinically and electrophysiologically normal parents who could well be said to have an autosomal recessive form of demyelinating neuro- 
TABLE 6 Genetic heterogeneity in Charcot-Marie-Tooth disease

\begin{tabular}{|c|c|c|}
\hline Mode of inheritance & $\begin{array}{l}\text { Demyelinating } \\
\text { neuropathy }\end{array}$ & Neuronal neuropathy \\
\hline Autosomal dominant & $\begin{array}{l}\text { Dyck and Lambert } 8 \\
\text { Thomas and Calne } 5 \\
\text { Thomas et al }{ }^{11} \\
\text { Harding and Thomas } 6 \\
\text { Present study }\end{array}$ & $\begin{array}{l}\text { Dyck and Lambert } 9 \\
\text { Thomas and Calne } \\
\text { Thomas et al }{ }^{11} \\
\text { Harding and Thomas } 6 \\
\text { Present study }\end{array}$ \\
\hline Autosomal recessive & $\begin{array}{l}\text { Dyck and Lambert } 8 \\
\text { Thomas and Calne } 5 \\
\text { Harding and Thomas } 6\end{array}$ & $\begin{array}{l}\text { Harding and Thomas } 6 \\
\text { Present study }\end{array}$ \\
\hline $\mathrm{X}$ linked recessive & $\begin{array}{l}\text { Present study- } \\
\text { ?family } T\end{array}$ & $\begin{array}{l}\text { No information } \\
\text { available }\end{array}$ \\
\hline $\mathrm{X}$ linked dominant & $\begin{array}{l}\text { No information } \\
\text { available }\end{array}$ & $\begin{array}{l}\text { No information } \\
\text { available }\end{array}$ \\
\hline
\end{tabular}

pathy, although this was not the authors' interpretation. Thomas and Calne ${ }^{5}$ suggested autosomal recessive inheritance in two pairs of affected sibs, and Harding and Thomas ${ }^{6}$ added two more pairs. These authors also comment on two families, both with parents who were first cousins, showing autosomal recessive inheritance of the neuronal type of neuropathy. This form of inheritance was also observed in the present study (ARN type) and its clinical features carefully analysed.

We believe that this is a true genotype since affected subjects in the families all had a severe form of the disease as discussed above (for example, see fig 3 where their gross degree of peroneal muscle weakness is apparent). All living parents and sibs were examined clinically and had motor nerve conduction measurements, but they showed no abnormalities.

Pratt $^{22}$ has presented the accepted evidence for both $\mathrm{X}$ linked recessive and $\mathrm{X}$ linked dominant genotypes, and this has been discussed further by Harding and Thomas. ${ }^{7}$ Family $T$ described here is a possible example of $X$ linked recessive inheritance of a demyelinating neuropathy (XRD) in two affected brothers. An alternative interpretation is that it is another ADD type family with the mother having an equivocal motor nerve conduction velocity, although it should be noted that all other affected females in
ADD families diagnosed on MNCV had physical signs of peripheral neuropathy, but the mother of family $\mathrm{T}$ did not.

Motor nerve conduction velocity (MNCV) measurement may be used to divide cases into demyelinating or neuronal (HMSN types I and II) types of peripheral neuropathy as described here and by others, ${ }^{6}$ but it has limitations. Peroneal nerve studies may be difficult and unreliable because of advanced denervation in the extensor digitorum brevis muscle. While median nerve motor conduction velocity has been proposed as the best method of separating cases by some workers, ${ }^{13}$ others ${ }^{14}$ suggest that sural nerve sensory measurements give a more reliable division. Within the neuronal genotypes (ADN and ARN) of this study and others, ${ }^{11} 14$ motor nerve measurements cannot distinguish clinically affected from normal. Furthermore, in the present study in a family with autosomal dominant inheritance, the proband had HMSN type I (MNCV median $19 \cdot 2 \mathrm{~ms}^{-1}$ ) and his clinically affected father had HMSN type II (MNCV median $51.0 \mathrm{~ms}^{-1}$ ), although MNCV in his peroneal nerve was reduced to $30 \cdot 4 \mathrm{~ms}^{-1}$.

The main purpose of this study was to relate phenotypic features to different genotypes identified within a population. While no absolute distinguishing characteristics exist between the genotypes, certain phenotypic patterns are associated with each genotype. These are summarised in table 7 and have been detailed above. Age of onset was not found to be a reliable differentiating characteristic, and it is suggested that Allan's rule, as first enunciated, ${ }^{15}$ is too simple for the present concept of Charcot-MarieTooth disease.

These findings with regard to clinical phenotypic features, measurement of motor nerve conduction velocity, and the degree of genetic heterogeneity in Charcot-Marie-Tooth disease have important implications in genetic counselling. Within the genotypes there are apparent sex differences in expression. For a male case all Mendelian modes of

TABLE 7 Phenotypic features associated with three genotypes identified

\begin{tabular}{|c|c|c|c|}
\hline Feature & $A D D($ families $A-J)$ & ADN (families $K, L, M$ ) & $A R N($ families $N-S)$ \\
\hline Sexes & Males more severe & & Sexes equally severe \\
\hline Symmetry of leg involvement & $\begin{array}{l}\text { Commonly asymmetrical } \\
\text { until advanced disease }\end{array}$ & Asymmetry occurs & Usually symmetrical \\
\hline Muscle weakness & Progressive with age & May not be marked & $\begin{array}{l}\text { Proximal and distal leg and } \\
\text { hand involvement at young age }\end{array}$ \\
\hline Muscle wasting & Increases with age & May not be marked & Present at young age \\
\hline Tendon reflex loss & $\begin{array}{l}\text { Almost always in legs, } \\
\text { commonly many lost }\end{array}$ & Usually preserved & Lost in arms and legs \\
\hline Sensory loss & More extensive with age & Present & $\begin{array}{l}\text { More than one modality } \\
\text { lost early on }\end{array}$ \\
\hline $\begin{array}{l}\text { Tremor and/or scoliosis } \\
\text { Max MNCV (median) }\end{array}$ & $\begin{array}{l}\text { Common } \\
<30 \mathrm{~ms}\end{array}$ & $\begin{array}{l}\text { Occurs } \\
>40 \mathrm{~ms}\end{array}$ & $\begin{array}{l}\text { Not seen in this series } \\
>40 \mathrm{~ms}\end{array}$ \\
\hline
\end{tabular}


inheritance are possible, but particular attention should be paid to a full clinical and investigative assessment of the mother who may well be asymptomatic. Similarly, a sister of an affected male in an ADD genotype family may regard herself as normal, but clinical examination might suggest she is affected and investigation will be needed to confirm this. A severely affected young woman suggests a genotype other than ADD or ADN. In this series the worse female cases were of ARN genotype. In the ADN genotype clinical manifestations may be mild even in men. If the tendency for females to be less severely affected than males is true of the ADN as well as the ADD genotype, then it would be easy to miss affected mothers and sisters on clinical examination. In this situation, measurement of motor nerve conduction velocity alone is of no help either in distinguishing normal from affected, and sensory nerve studies are needed. $X$ linked types are still ill-defined, if they exist at all. In the possible example described here the clinical features of the two young brothers were like those of the ADD genotype which this family may indeed have been. However, the possibility of true $\mathrm{X}$ linked types must be borne in mind when advising an isolated male case.

Dr A P Brooks was a Medical Research Council Training Fellow in the University Department of Human Genetics, Edinburgh.

\section{References}

1 Charcot JM, Marie P. Sur une forme particulière d'atrophie musculaire progressive souvent familiale débutant par les pieds et les jambes et atteignant plus tard les mains. Rev Med 1886;6:97-138.

2 Tooth HH. The peroneal type of progressive muscular atrophy. MD thesis, University of Cambridge. London: Lewis, 1886.

3 de Recondo J. Hereditary neurogenic muscular atrophies (Charcot-Marie-Tooth disease). In: Vinken PJ, Bruyn GW, eds. Handbook of clinical neurology. Vol 21. System disorders and atrophies. Part I, chap 13. Amsterdam: North Holland, 1975.
4 Brooks AP. Heterogeneity in peroneal muscular atrophy. MD thesis, University of Sheffield, 1979.

5 Thomas PK, Calne DB. Motor nerve conduction velocity in peroneal muscular atrophy: evidence for genetic heterogeneity. J Neurol Neurosurg Psychiatry 1974;37: 68-75.

6 Harding AE, Thomas PK. The clinical features of hereditary motor and sensory neuropathy types I and II. Brain 1980;103:259-80.

7 Harding AE, Thomas PK. Genetic aspects of hereditary motor and sensory neuropathy (types I and II). J Med Genet 1980;17:329-36.

8 Dyck PJ, Lambert EH. Lower motor and primary sensory neuron diseases with peroneal muscular atrophy. I. Neurologic, genetic, and electrophysiologic findings in hereditary polyneuropathies. Arch Neurol $1968 ; 18$ :603-18.

9 Dyck PJ, Lambert EH. Lower motor and primary sensory neuron diseases with peroneal muscular atrophy. II. Neurologic, genetic, and electrophysiologic findings in various neuronal degenerations. Arch Neurol 1968;18: 619-25.

10 Dyck PJ. Definition and basis of classification of hereditary neuropathy with neuronal atrophy and degeneration. In: Dyck PJ, Thomas PK, Lambert EH, eds. Peripheral neuropathy. Vol II, chap 37. Philadelphia: Saunders, 1975.

11 Thomas PK, Calne DB, Stewart G. Hereditary motor and sensory polyneuropathy (peroneal muscular atrophy). Ann Hum Genet 1974;38:111-53.

12 Pratt RTC. Disorders of the cranial and peripheral nerves, and the sensory syndromes. In: The genetics of neurological disorders. Chap 8. London: Oxford University Press, 1967.

13 Bradley WG, Madrid R, Davis CJF. The peroneal muscular atrophy syndrome-clinical, genetic, electrophysiological, and nerve biopsy studies. Part 3. Clinical electrophysiological and pathological correlations. $J$ Neurol Sci 1977;32:123-36.

14 Buchthal F, Behse F. Peroneal muscular atrophy (PMA) and related disorders. I. Clinical manifestations as related to biopsy findings, nerve conduction and electromyography. Brain 1977;100:41-66.

15 Allan W. Relation of hereditary pattern to clinical severity as illustrated by peroneal atrophy. Arch Intern Med 1939;63:1123-31.

Requests for reprints to Dr A P Brooks, Department of Medicine, Addenbrooke's Hospital, Hills Road, Cambridge CB2 2QQ. 